\title{
Assessment of Intraspecific Genetic Variation Between Three Morphotypes of Cissus quadrangularis using CCMP Markers
}

\author{
Ritesh Kaur and C. P. Malik* \\ School of Life Sciences, Jaipur National University, Jaipur, 302017, India
}

Key words: Consensus chloroplast microsatellite primers. Morphotypes. Cissus quadrangularis, Genetic relationship, Sequencing

\begin{abstract}
The objective of the current study was to assess and establish intraspecific variation between three morphotypes of Cissus quadrangularis using ten Consensus Chloroplast Microsatellite Primers. Significant level of genetic variation was detected between the three morphotypes. Sequence analysis of the CCMP PCR fragment showed the high degree of similarity to the chloroplast genome sequences of other Vitaceae members indicating that these regions are highly conserved.
\end{abstract}

\section{Introduction}

Cissus quadrangularis L. (Vitaceae) is an important medicinal plant found in India and Africa, commonly known as "Hadjod and bone setter". As the name indicates it is commonly used in bone healing activity and well known in Ayurveda since long (Nagani et al. 2011). C. quadrangularis is a succulent shrubby climber with 4-winged internodes and a tendril at the nodes (Haines 1925) and reaches a height of $1.5 \mathrm{~m}$ approximately. Stem jointed at nodes, internodes are 8 to $10 \mathrm{~cm}$ long and 1.2 to $1.5 \mathrm{~cm}$ wide. Leaves are simple, lamina ovate or reniform, $\pm 5 \mathrm{~cm}$ wide, base truncate-cordate, crenate-serrate; petiole $\pm 2 \mathrm{~cm}$ long (Panda and Das 2004, The Wealth of India 2005). Flowering is very rare and flowers are small, greenish white, bisexual, tetramerous and opposite to the leaves. Fruit globose/obovoid fleshy berries. It is vegetatively propagated mainly in the month of June and July. Propagation through seeds is unreliable because seeds are rare and not viable. Three variants in the species were identified based on stem morphology and these are square winged, round stem

*Author for correspondence. <cpm_malik@yahoo.com>. 
and flattened stem mentioned here as morphovariant I, II and III, respectively (Kaur and Malik 2014) (Fig. 1a, b and c). Combined data of phenology, chemical analyses and molecular biology (RAPD, ISSR) have been discussed to understand genetic relationship between the three morphotypes. The two morphotypes (I and III) appear to be similar in regard to chemicals, leaf morphology (Fig. 2 a, b and c) and genetic makeup. Morphotype II appears to be divergent in regard to leaf shape, leaf colour, stem structure, having specific chemicals and with regard to molecular biology. A dendrogram based on similarity coefficient was generated by using the unweighted pair group method arithmetaic mean (UPGMA). On the basis of combined RAPD and ISSR analyses morphovariant I and III showed $0.65 \%$ similarity with each other and morphovariant I and II and II and III showed $0.34 \%$ similarity with each other. The figures emerging from analyses of combined data (morphology, chemical analyses and molecular biology) support the divergence of morphotype II from the other two types (Kaur and Malik 2014).

The objective of the present investigation was to evaluate the efficacy of CCMP marker in assessing their genetic relationship.

\section{Materials and Methods}

Three morphovariants were collected from JNKVV, Jabalpur (M.P.) and were distinguishable on the basis of stem and leaf morphology (Figs 1 and 2).

Genomic DNA was extracted from young leaves sampled from three morphotypes using modified CTAB method (Tiwari et al. 2012).

Ten consensus chloroplast microsatellite primers ( $\mathrm{cmp} 1$ to 10) specific to chloroplast genomes of dicotyledonous angiosperms (Weising and Gardner 1999) were used for characterization of organellar genome of three morphovariants of Cissus quadrangularis. The PCR amplifications were carried out in a $10 \mu \mathrm{l}$ reaction mixture containing $100 \mathrm{ng}$ of genomic DNA, 1X PCR buffer containing $1.5 \mathrm{mM} \mathrm{MgCl}, 0.4 \mu \mathrm{M}$ each of forward and reverse primers, 150 $\mu \mathrm{M}$ of each dNTPs and 0.6U of Taq DNA polymerase (Bangalore Genei, India). PCR amplifications were performed in GeneAmp 9700 thermal cycler (Perkin Elmer Applied Biosystems) with the following cycling conditions: $94^{\circ} \mathrm{C}$ for $4 \mathrm{~min}$; 35 cycles of $92^{\circ} \mathrm{C}$ for $30 \mathrm{~s}, 55^{\circ} \mathrm{C}$ for $30 \mathrm{~s}$, and $72^{\circ} \mathrm{C}$ for $45 \mathrm{~s}$; and a final extension at $72^{\circ} \mathrm{C}$ for $5 \mathrm{~min}$. The amplified PCR products were resolved by electrophoresis on $4 \%$ agarose (Bangalore Genei, India) gel and visualized by ethidium bromide staining. Banding pattern was recorded under ultraviolet light and documented in Alpha Innotech Fluorchem gel documentation system. As the amplification products that resulted from CCMP markers were run on agarose gels and the 
variation due to single base changes could not be detected credibly; hence, all the amplicons were subjected to sequence analysis (Basha and Sujatha 2009).
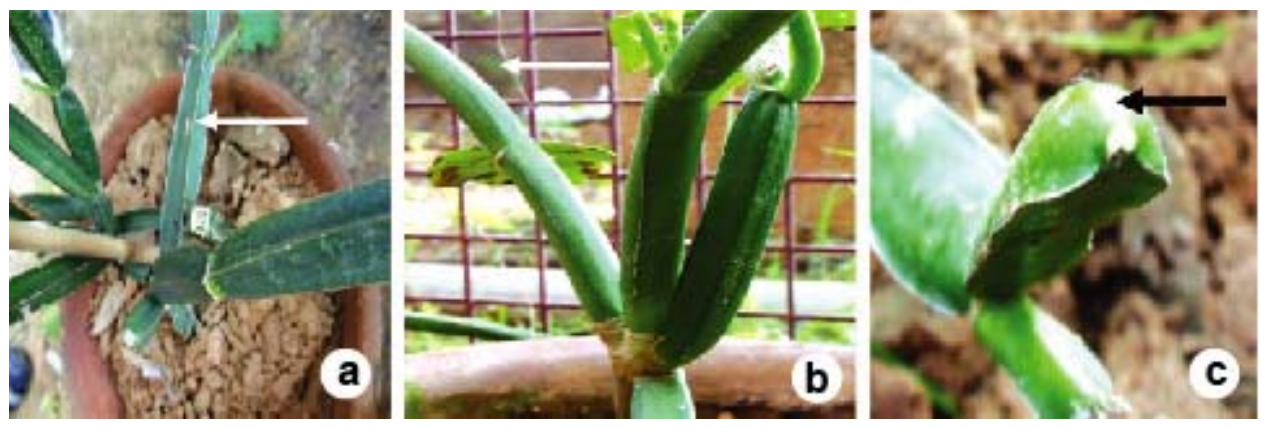

Fig. 1. (a) Morphovariant I having quadrangular stem, (b) Morphovariant II with rounded stem and (c) morphovariant III having triangular internodes.
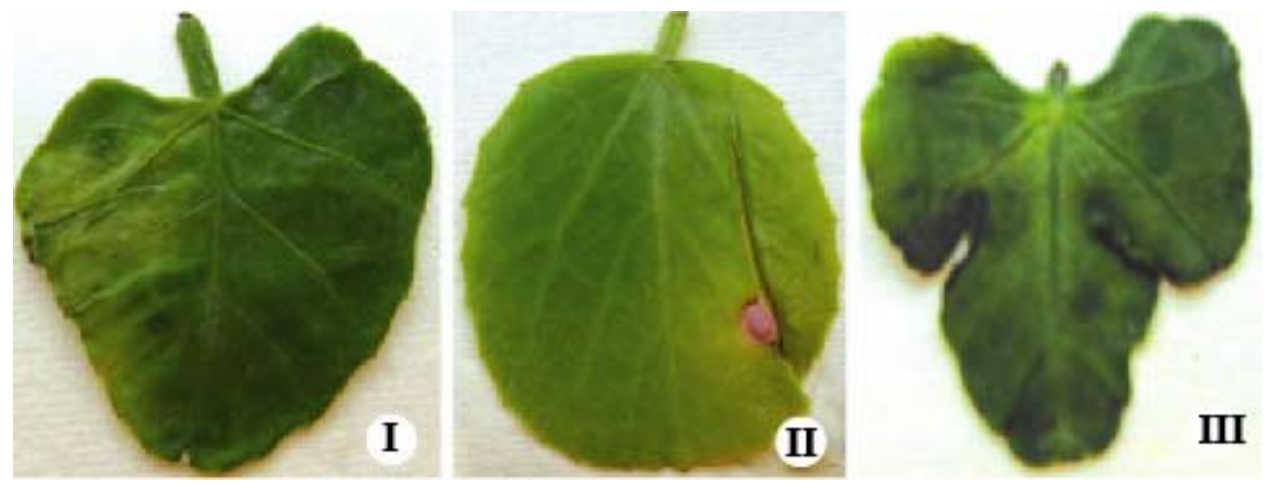

Fig. 2 Leaf morphology of three morphovariants.

PCR products amplified with three ccmp primer pairs were ligated into pTZ57R (Insta) T/A cloning vector using cloning kit (MBI Fermentas, USA). The recombinant plasmids were transformed into competent $E$. coli cells (DH5a) and the plasmid DNA purified from the white colonies as described by Sambrook et al. (1989). Selected transformed clones were screened by PCR analysis with corresponding ccmp primer pairs and the size of inserts was checked by EcoRI and HindIII restriction digestion. The inserted DNA fragments were sequenced at Bioserve Biotechnologies (Hyderabad, India) using M13 vector specific primers. For each amplicon, two sequences were cloned and subjected to sequence analysis. Sequences were edited and assembled in Chromas 1.45 and multiple sequence alignments were performed using Genetool Lite 1.0 software. Alignments were adjusted manually where necessary. 


\section{Results and Discussion}

The three morphotypes were distinguishable on the basis of leaf and stem morphology. Morphovariants I and III had variable leaf margin in regard to shape and denting (Fig. 2). Morphotype I was four - winged with young leaves $3.5 \mathrm{~cm}$, deep green, shinning. The leaves were cuneate in both the types. In morphotype III, stem was triangular in shape having smooth edges, and leaves were $2.5-3.5 \mathrm{~cm}$, lobed with slightly wavy margins without dents when young. They were deep green shinning. Morphotype I had leaves $3.5 \mathrm{~cm}$ and young ones were not lobed but wavy, deep green shinning, internode was four - angled with prominent angles.

In morphovariant II, leaves were $5 \mathrm{~cm}$, yellowish green, dull, non cuneate, leaf margins denticulate, lamina thick, internodes round with thin line as an edge (Fig. 2).

With a view to assessing genetic relationships among the three morphovariants and to evaluate the organelle specific primers polymorphism, and identification of phylogenetic relationship consensus chloroplast microsatellite primers were tested. Out of ten primers, three primers specific to chloroplast gave amplification product. Allele size of amplification products (bp) from three morphovariants (Fig. 3) generated by consensus chloroplast microsatellite primers (ccmp) are set in Table 1.

Table 1. Allele size of the amplification products generated by consensus chloroplast microsatellite primers.

\begin{tabular}{cccc}
\hline Morphovariant & \multicolumn{3}{c}{ Size of amplification product (bp) } \\
\cline { 2 - 4 } & ccmp2 & ccmp3 & ccmp4 \\
\hline I & 210 & 120 & 145 \\
II & 212 & 120 & 146 \\
III & 210 & 120 & 144 \\
\hline
\end{tabular}

Sequence analysis of amplicons obtained using organelle specific primers was done. The ccmp 3 primer sequence flanking trnG intron region revealed $100 \%$ homology in three morphovariants. Sequences derived with ccmp 2, ccmp 3 and ccmp 4 showed high degree of similarity to the chloroplast genome sequences of other Vitaceae members indicating that these regions are highly conserved. The ccmp 2 sequence of three morphovariants possessed $83-92 \%$ homology to Vitis vinifera subsp. caucasica chloroplast DNA, another member of the family Vitaceae. 
The sequence derived with ccmp 4 primers had 80 - 95\% similarity to Vitis vinifera subsp. caucasica chloroplast DNA. The property of inheritance of organellar genomes and its low nucleotide substitution rate has encouraged us to use organelle specific primers from heterologous systems and were used for assessment of genetic relationships among three morphovariants of Cissus.

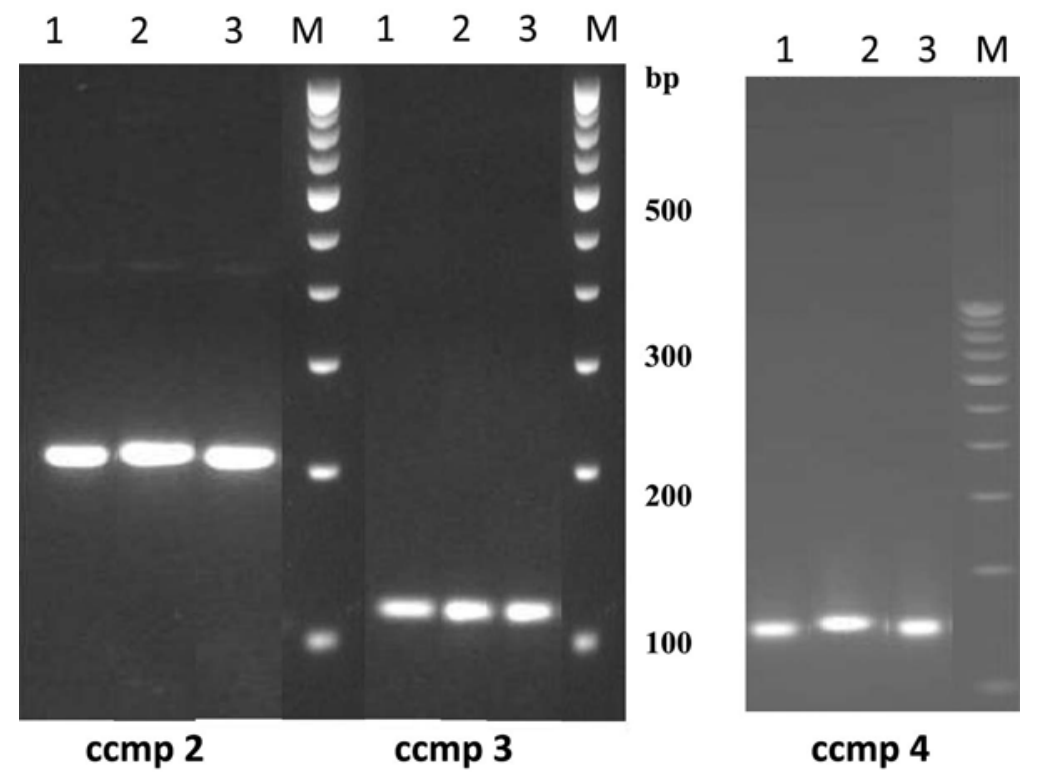

Fig. 3. Portray the gel profiles obtained from CCMP primers 2, 3 and 4.

Molecular markers unfold more rapidly and accurately genetic differences which are more reliable than morphological or biochemical methods without the interference of environment. However, nuclear and plastid DNA analysis constitute an important tool for phylogenetic and diversity analysis of plant species. Most workers have inferred that RAPD and ISSR markers were not affected by the environmental conditions and the latter are more specific in pronouncing genetic variation between different taxa. Leela (2005) through molecular markers inferred that the two morphotypes of Cissus i.e. square stemmed and round stemmed forms same clusters and genetically similar. The possibility of the three morphovariants, having diverged from a single common ancestor is surmised, and in all probability experiencing genetic evolution. To investigate chloroplast variation, universal primers targeted to mononucleotide repeats occurring in chloroplast genome. Moreover, chloroplast specific microsatellites were used to evaluate the interspecific polymorphism, the detection of hybridization and introgression and phylogeny of plant population. 
With the view to assessing genetic relationship among the three morphovariants i.e morphovariant I, II and III, consensus chloroplast microsatellite primers were used.

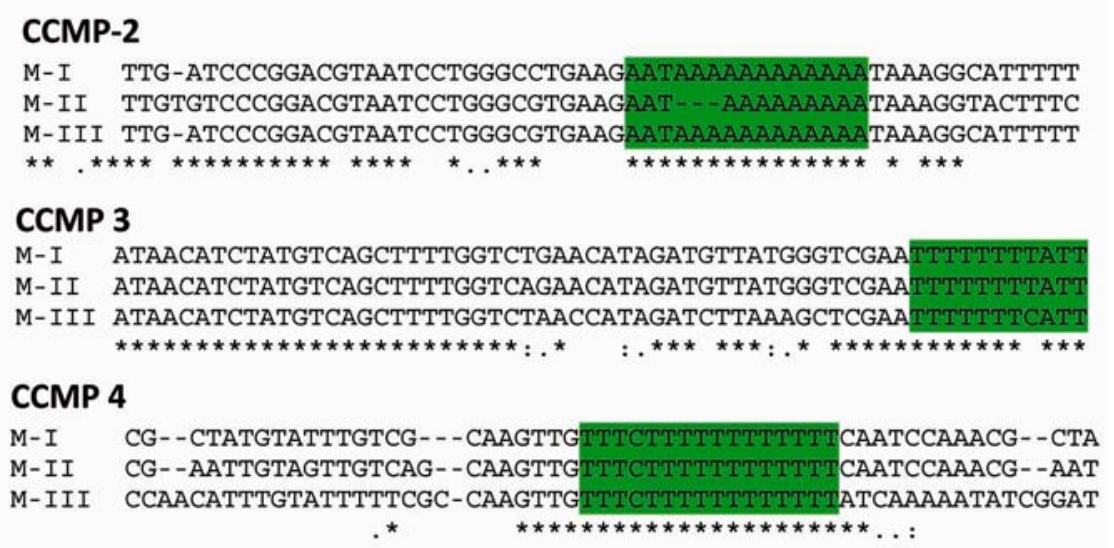

Fig. 4. Sequence variation: Alignment of DNA sequences at the consensus chloroplast microsatellite primers ccmp 2, ccmp 3 and ccmp 4 locus from three morphovariants of Cissus. Only unique sequences are shown for each species. Microsatellites are shown in colour with repeat.

Three primers specific to chloroplast genome (ccmp 2, 3 and 4) gave amplification products. Based on our studies it appears that through consensus chloroplast microsatellite primers it was possible to generate allele sizes of amplification products from three morphovariants. Allele sizes of amplification products (bp) from three morphovariants of Cissus quadrangularis generated by ccmp primers are set in Table 1 (Fig. 4). PCR amplification of three morphovariants of Cissus quadrangularis with primers 2 and 4 made interesting revelation. Very small differences were observed in allele size of the three morphovariants. Primer ccmp 3 yielded a single discrete PCR product.

Three morphotypes of Cissus were genotyped with 10 consensus chloroplast microsatellites primers (CCMP). In CCMP primers, variation in number of mononucleotide repeats is the cause of polymorphism. Out of 10 generic primers, CCMPs 2 and 4 showed size polymorphism (Fig. 4) while amplicons with CCMP primers 2, 3 and 4 showed sequence variation with regard to the repeat length motifs (Table 2). In CCMP 2 primer, mononucleotide repeat is " $\mathrm{A}$ ". Morphovariant I had 12 nucleotides, II had 9 " $\mathrm{A}$ "nucleotides while III had 12 " $\mathrm{A}$ " nucleotides. With regard to CCMP primer 3, variation was observed only with regard to nucleotide change in morphovariant III, while it was 8 "T"nucleotides in all the samples. CCMP 4 primer gives mononucleotide repeats of " $\mathrm{T}$ ". Morphovariant I gave an amplicon of $145 \mathrm{bp}$ size and the repeat region was $(\mathrm{T})_{12}$, morphovariant II gave an amplicon of $146 \mathrm{bp}$ and the repeat region is $(\mathrm{T})_{12}$, while 
inmorphovariant III, the amplicon length was 144 and the repeat region length was $(\mathrm{T})_{12}$ (Table 2). Small differences were observed in allele sizes of three morphotypes with ccmp 2, ccmp 3 and ccmp 4. Use of ccmp 2, ccmp 3 and 4 primer sets on three morphovariants clearly showed that all three morphotypes are genetically similar (Fig. 4).

Table 2. Repeat motifs with ccmp primers.

\begin{tabular}{|c|c|c|c|c|c|c|}
\hline \multirow[b]{2}{*}{ Morphovariant } & CCMP 2 & \multirow{2}{*}{$\begin{array}{c}\text { Toba- } \\
\text { cco }\end{array}$} & ССMP 3 & \multirow{2}{*}{$\begin{array}{c}\text { Toba- } \\
\text { cco }\end{array}$} & CCMP 4 & \multirow{2}{*}{$\begin{array}{l}\text { Toba- } \\
\text { cco }\end{array}$} \\
\hline & $\begin{array}{l}\text { Repeat region } \\
\text { in Cissus }\end{array}$ & & $\begin{array}{l}\text { Repeat region } \\
\text { in Cissus }\end{array}$ & & $\begin{array}{l}\text { Repeat region } \\
\text { in Cissus }\end{array}$ & \\
\hline I & (A)12 & (A)11 & $(\mathrm{T}) 8$ & (T)11 & $(\mathrm{T}) 12$ & $(\mathrm{~T}) 13$ \\
\hline II & (A) 9 & & $(\mathrm{~T}) 8$ & & (T)12 & \\
\hline III & (A)12 & & (T)7 and $\mathrm{C}$ & & $(\mathrm{T}) 12$ & \\
\hline
\end{tabular}

In chloroplast genomes, gene order is highly conserved but small insertions/deletions (indels) are relatively frequent resulting in intra-species variation (Turkec et al. 2006). The possible explanations for existence of mutational hotspots in noncoding cpDNA or due to small insertion and deletion mutations in the intergenic cpDNA regions has been adequately discussed (Johnson and Hattori 1996, van Ham et al. 1994). Regardless of the causes of genetic variation, characterization of chloroplast genome of Cissus quadrangularis using universal primers targeted to mononucleotide repeat regions indicates that ccmp primers 2, 3 and 4 serve as a useful tool for assessment of intraspecific genetic variation.

\section{Acknowledgment}

Special thanks are due to Dr. Sujatha Mulpuri, Principal Scientist, Directorate of Oil Seed Research, Hyderabad for providing facilities to undertake molecular biology work and for general discussion.

\section{References}

Basha SD and Sujatha M (2009) Genetic analysis of Jatropha species and interspecific hybrids of Jatropha curcasusing nuclear and organelle specific markers. Euphytica 168: 197-214.

Haines H (1925) The Botany of Bihar and Orissa. Adland \& Sons, West Newman Ltd. 1921-1925 London.

Johnson DA and Hattori J (1996) Analysis of a hotspot for deletion formation within the intron of the chloroplast trnL gene. Genome 39: 999-1005.

Kaur R and Malik CP (2014) Cissus quadrangularis L - Its botany, chemistry and medicinal importance: A Review. Intl. J. Pharm. Clin. Res. 6(1): 27-35. 
Kaur R and Malik CP (2014). Genetic and biochemical fingerprinting of three morphotypes of Cissus quadrangularis using RAPDs and ISSRs. Nucleus DOI 10.1007/s13237-014-0103: 57(1): 45-53.

Leela Ravishankar, Anand KV, Lalitha Murthy BNS and Prakash GS (2005) Pharmacognostical and phytochemical evaluation of stem of Cissus quadrangularis L. Indian J. Horticult. 62(3): 219- 22.

Nagani VK, Kevalia J and Chanda SV (2011). Pharmacognostical and phytochemical evaluation of stem of Cissus quadrangularis L. Intl. J. Plant Sci. Res. 2(11): 2856-2862.

Panda S and Das AP (2004) Flora of Sambalpur, Dishen Singh Mahendra Pal Singh, Dehradun, Pharmacological Investigation of Certain Medicinal Plants and Compound Formulations Used in Ayurveda and Siddha, Central Council for Research, In Ayurveda and Siddha, 2004. New Delhi.

Sambrook J, Fritsch EF and Maniatis T (1989) Molecular cloning. A laboratory manual, $2^{\text {nd }}$ ed. CSH Laboratory Press, Cold Spring Harbour, New York.

The Wealth of India, 2005.

Tiwari KL, Jadhav SK and Gupta S (2012) Modified CTAB technique for I solation of DNA from some medicinal plants. Res. J. Med. Plant 6: 65-73.

Turkec A, Sayar M and Heinze B (2006) Identification of sweet cherry cultivars (Prunus avium L.) and analysis of their genetic relationships by chloroplast sequencecharacterised amplified regions (cpSCAR) Genet Resour Crop Evol. 53: 1635-1641.

van Ham RCHJ, Hart HT, Mes THM and Sandbrink JM (1994) Molecular evolution of noncoding regions of the chloroplast genome in the Crassulaceae and related species Curr. Genet. 25: 558-566.

Weising K and Gardner RC (1999) A set of conserved PCR primers for the analysis of simple sequence repeats polymorphism in chloroplast genomes of dicotyledonous angiosperms. Genome 42: 9-19. 